\title{
UN PEDESTAL DE ESTATUA CON INSCRIPCIÓN de Pajaritos (Huelva)
}

\author{
Helena Gimeno Pascual \\ Centro CIL II \\ Enrique C. Martín Rodríguez \\ Museo de Huelva \\ J. Aurelio Pérez Macías \\ Universidad de Huelva
}

Fecha de recepción: 10/06/2009

Fecha de aceptación: 03/03/2010

Resumen

Un pedestal con la dedicación de un aedilis y IIvir, de la tribu Quirina, confirma el estatus jurídico privilegiado de Onoba Aestuaria y descarta la condición jurídica de colonia para Onoba. Este pedestal apareció en la finca Pajaritos, cerca del cruce (Cuatro Caminos) de las vías Ab Ostio Fluminis Anae-Italica y Onoba-Pax Iulia.

Palabras clave

Huelva, Pedestal, inscripción, IIvir, Quirina, Municipio

\section{AbSTRACT}

A pedestal set up by an aedile and IIvir enrolled in the Roman voting tribe Quirina confirms Onoba Aestuaria's privileged juridical status and calls into question the commonly held view that Onoba had the juridical status of a colony. This pedestal appeared in Pajaritos site, near crossing place (Cuatro Caminos) of the roman roads Ab Ostio Fluminis Anae-Italica and Onoba-Pax Iulia.

\section{KeY WORDS}

Onoba, pedestal, inscription, IIvir, Quirina, municipality

\section{Circunstacias del hallazgo.}

Durante la realización de labores agrarias, en el año 2004, apareció en una torrentera paralela al carril que conduce a la entrada de la finca Pajaritos y muy próxima a la rivera de La Anicoba, un pedestal de estatua con inscripción (figura 1). Se hallaron también en el mismo punto restos de un edificio, entre ellos un pavimento de ladrillos y una piedra gorronera de puerta, del mismo material calizo que el pedestal. Tras conocer este hallazgo en el año 2007 el Servicio de Protección de la Naturaleza de la Guardia Civil, contactó con el propietario de la finca, D. Leonardo Gavilán Camacho, que accedió de inmediato a su entrega.

El Seprona comunicó el descubrimiento a la Delegación Provincial de Cultura de la Junta de Andalucía en Huelva, y finalmente se procedió a la recogida y a su traslado 

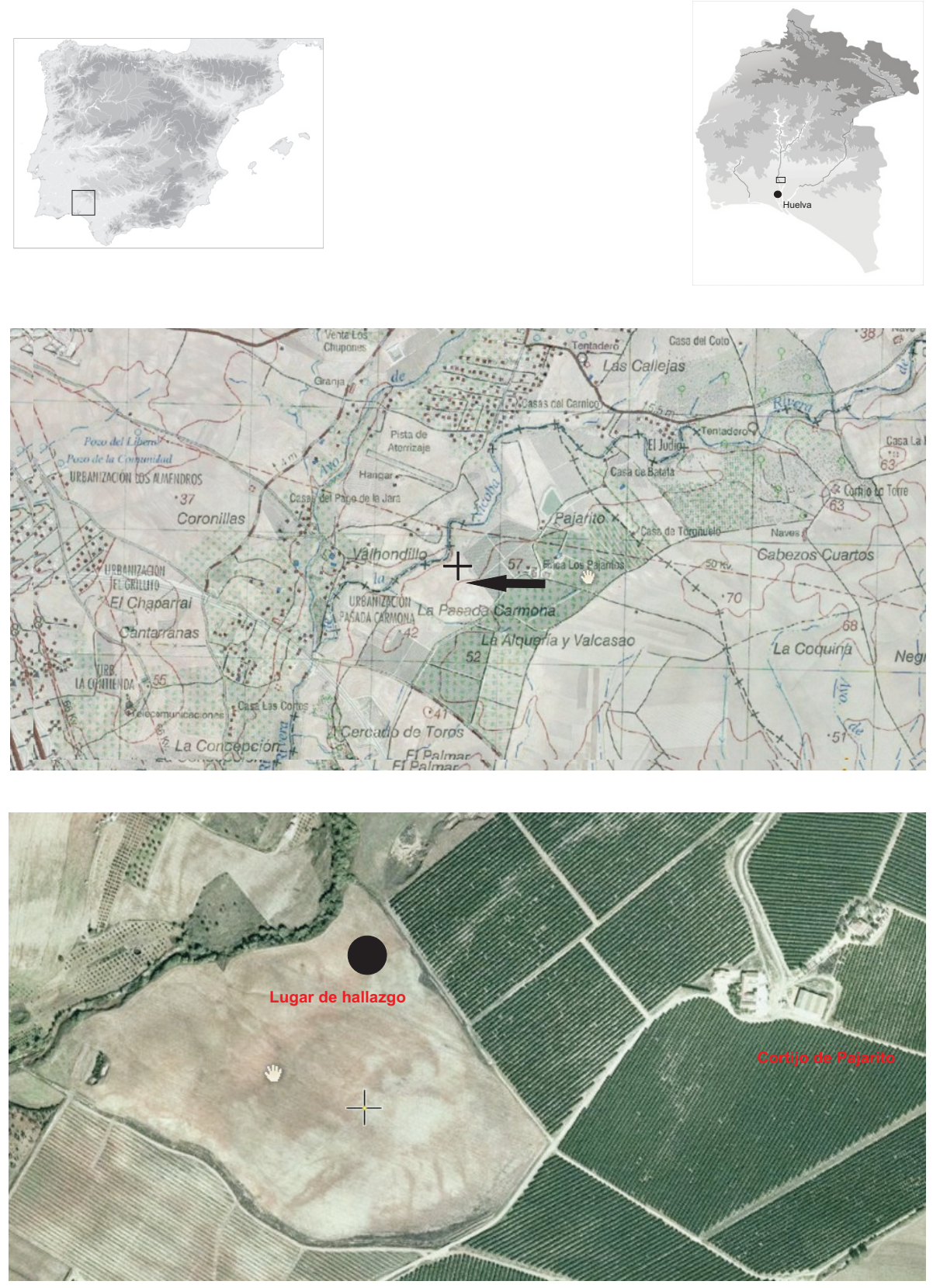

Huelva EN SU HISTORIA - 2 a ÉPOCA • Vol. 13 • 2010 • [00-00] • ISSN 1136-6877 @ Universidad de Huelva 
al Museo de Huelva, donde se encuentra expuesto en la zona de jardín debido a su peso.

El ASENTAMiento de PAJARitos.

El asentamiento de Pajaritos se encuentra al Noroeste del término municipal de Huelva (figura 2), a 8,4 km del casco urbano, en el vértice de unión con los de Gibraleón y Trigueros, en las coordenadas 684.657.70/4.136.814.73 (Huso 29). Formaba parte del conjunto de explotaciones agrícolas romanas que rodeaban el entorno de la ciudad de Huelva.

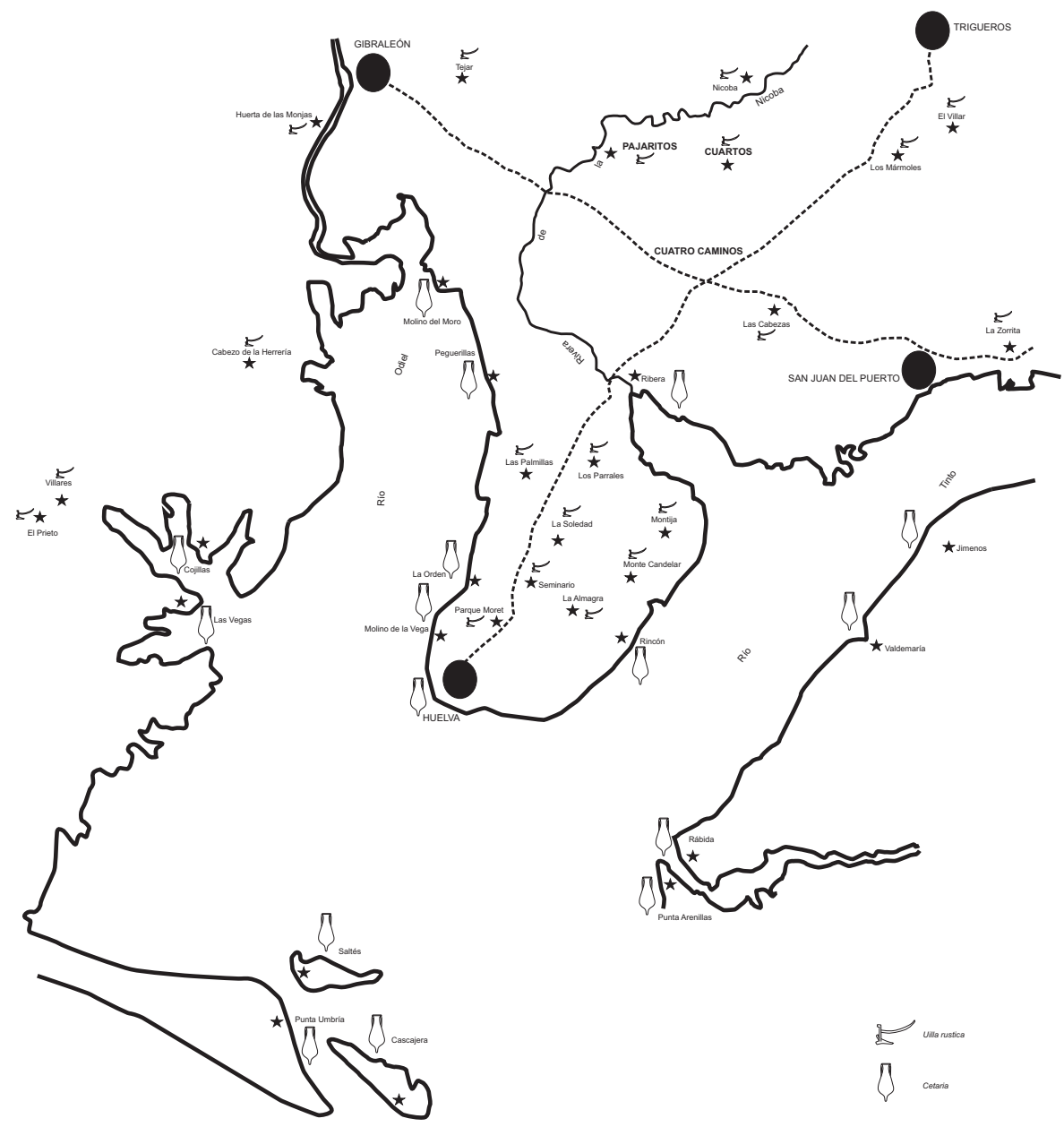


Además del pedestal de estatua con inscripción (figura 3), se detecta el yacimiento en superficie por la abundancia de material cerámico, muy desmenuzado por la acción de los tractores y el aterrazamiento para la siembra de naranjos, el principal cultivo de la finca junto con los girasoles. En el lugar de aparición del pedestal se recogió también, como ya se ha indicado, una piedra gorronera para cobijar la tranca de madera de una puerta (figura 4), lo que hace suponer que aquél se encontraba más que en una simple domus rural en un edificio de cierta envergadura, pues este tipo de gorroneras sólo se utilizan para atrancar puertas de gran porte, como las de las murallas. Los restos se encontraron en una suave ladera junto a la llanura de inundación

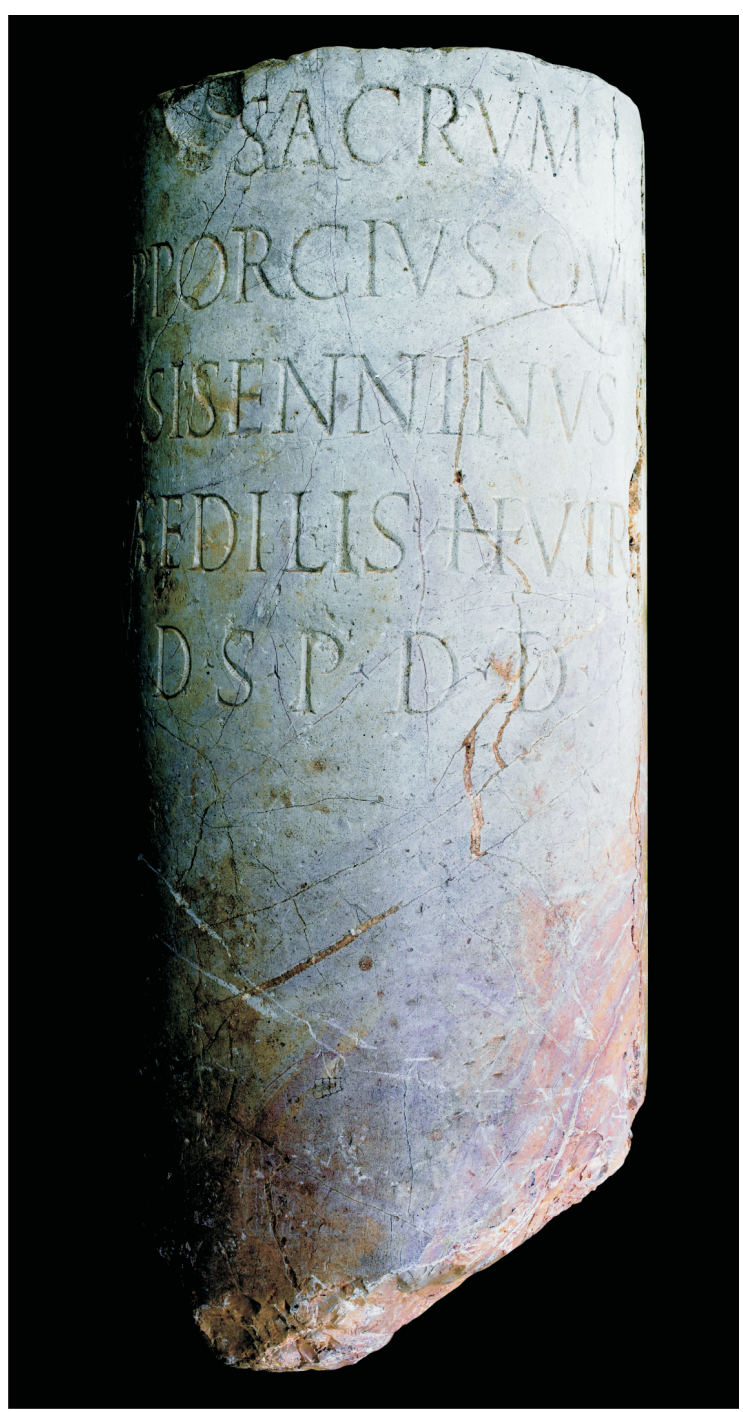
de la rivera de La Anicoba. Los restos cerámicos del yacimiento se extienden por toda la pendiente en una dispersión aproximada de unas dos hectáreas. Aunque no es posible determinar con exactitud la cronología del asentamiento, la abundancia de pastas de cerámicas africanas de cocina y algunos galbos de Sigillata Africana $\mathrm{D}$ permiten un primer acercamiento, que puede situarse en líneas generales en época bajo-imperial. Podemos determinar así que el pedestal de Pajaritos se encontraba en un edificio de cierta significación en una villa rustica que al menos estaba ocupada en época bajo imperial, desde el siglo IV d.C. Nuestra impresión es que este pedestal fue reaprovechado en época tardoantigua en un edificio de aparato, probablemente una basílica paleocristiana adscrita a la villa rústica, pues, como describiremos a continuación, fue retallado en el coronamiento para eliminar el nombre de la dedicación.

Dentro del territorio que debió formar parte de la an- 


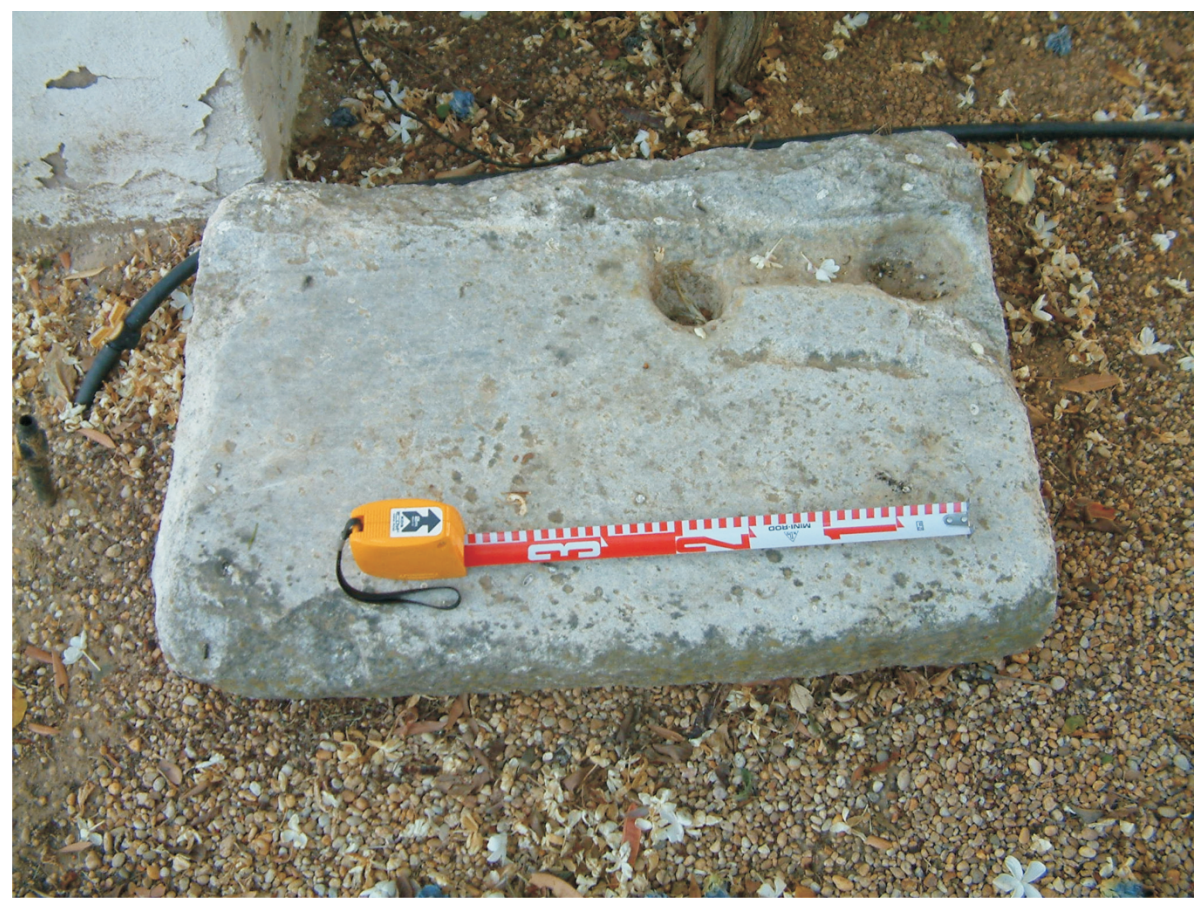

tigua Onoba, cuyos límites se prolongarían sin dudas por todo el estuario de los ríos Tinto y Odiel, el conocimiento de la implantación romana es irregular ${ }^{1}$. Carecemos de prospecciones sistemáticas que permitan conocer al detalle su modelo de colonización e implantación. Aún así, los datos conocidos avalan que la economía de la ciudad giró alrededor de dos ejes, los asentamientos dedicados a la pesca y sus derivados y los dedicados a la producción agrícola ${ }^{2}$.

La ubicación de Onoba, en una península rodeada por el Atlántico y las desembocaduras de los ríos Tinto y Odiel, era favorable para la proliferación de establecimientos pesqueros (cetariae), dedicados a la elaboración de salsas y salazones de pescado ${ }^{3}$. La categoría de estos asentamientos no es siempre la misma, desde la pequeña aldea (vicus maritimus), como El Eucaliptal en Punta Umbría, hasta las uillae ad mare. En algunos de ellos existen alfarerías (figlinae) para la producción de ánforas que permitían el envasado de cara a su comercialización. Aunque son conocidas las de Punta

1 Los restos romanos en el casco urbano de Huelva en J.M. CAMPOS CARRASCO, La ciudad romana de Onuba (Huelva), una revisión arqueológica, Anales de Prehistoria y Arqueología, 17-18,2002, 329-340.

2 Muchos de estos asentamientos están catalagados en N. VIDAL TERUEL, Análisis arqueológico de la romanización del territorio onubense, Huelva, 2007. Otros se deben a los trabajos del Grupo de Investigación "Territorio y Poder" (HUM 838), del Plan Andaluz de Investigación y Desarrollo.

3 Véase J.M. CAMPOS, J.A. PÉREZ, y N. VIDAL, Las cetariae del litoral onubense en época romana, Huelva, 1999. 
Umbría y Las Cojillas ${ }^{4}$, estas alfarerías se han documentado también en Torre de la Arenilla, La Ribera y Peguerillas. Entre los tipos anfóricos predominan las formas Beltrán IIB para época alto-imperial y las formas Keay XXII y XV en momentos bajo-imperiales, en un momento en el que se unifican los recipientes anfóricos en las costas sur-atlánticas hispanas. Este tipo de asentamientos se encuentran en la misma ciudad y alrededores (Molino de la Vega y La Orden), en las marismas del Odiel (Peguerillas, Molino del Moro, Las Cojillas, Las Vegas, y Punta Umbría), en parajes del estuario (Saltés-La Cascajera), y en el río Tinto (Rincón, Torre de la Arenilla, La Rábida, Valdemaría y Los Jimenos) y en su afluente de la rivera de La Anicoba (La Ribera). A tenor de los datos aportados por las excavaciones realizadas en algunas de ellas, el auge de estas industrias conserveras se produjo a los largo de los siglos IV y V d.C., aunque sus tímidos comienzos se inician en el siglo II d.C. Al contrario de lo que sucedía con la producción agrícola el cese total de la actividad se produjo en el siglo VI d.C. (figura 2)

No menor importancia debió ocupar la producción agrícola y ganadera (figura 2), sobre todo los cereales y otros cultivos de secano. La vid no parece estar representada a juzgar por la escasa presencia de sus recipientes de envasado, las ánforas Haltern 70, hasta el momento sólo documentadas en las uillae periurbanas, como El Seminario. Estos cultivos deberían alternar con la oleicultura, a la que deben asociarse las formas de las ánforas Dressel 20, pero sin alcanzar las cotas del monocultivo que se desarrolló en el valle del Guadalquivir. Sus cronologías se prolongan hasta bien entrado el siglo VI d.C., como nos indican las Sigillatas Focenses que aparecen en algunas de ellas.

La mayor parte de estos asentamientos agrícolas se encuentran con profusión en los suelos de mayor capacidad agrícola, las margas azules, también conocidas como Arcillas de Gibraleón, entre la ciudad de Huelva y la rivera de La Anicoba (Las Palmillas, Los Parrales, Montija, Monte Candelar, La Soledad, etc.) pero igual significación tienen en los términos de Gibraleón, Trigueros y Aljaraque (La Mata, Huerta de las Monjas, El Tejar, Los Mármoles, El Villar, Cabezo de La Herrería, Villares, El Prieto, etc.), que formarían parte del territorium de Onoba.

Su concentración es particularmente notable en relación al compitum de las dos vías que en época romana convergían en Huelva (figura 2), la que procedía del Guadiana con destino a Itálica (Ab ostio fluminis Anae Emeritam usque), y la que se dirigía al Norte, hacia Urium, Arucci y Pax Iulia 5 . El encuentro de estas dos vías no se produciría en Onoba, sino más allá de la rivera de La Anicoba, donde el cruce está fosilizado en el tóponimo Cuatro Caminos. Otro topónimo próximo, Cuartos, que aparece ya como alquería islámica (Quartos) en la división de términos entre Huelva, Niebla y

4 J.M. CAMPOS, J.A. PÉREZ, y N. DE LA O VIDAL, Alfares y producciones cerámicas en la provincia de Huelva. Balance y perspectivas, Figlinae Baeticae. Talleres alfareros y producciones cerámicas en la Bética romana (ss. II a.C.-VII d. C.), I, BAR International Series, 1266, 2004, 125-160.

5 Estas vías en M. BENDALA GALÁN, Ab ostio fluminis Anae...., Cuadernos de Prehistoria y Arqueología, 13-14,1987, 129-139; P. SILLIÉRES, Les voies de communication de l'Hispanie Méridionale, Paris, 1990; y J. M. RUIZ ACEVEDO, Las vias romanas en la provincia de Huelva, Huelva, 1998. 
Gibraleón en época de Alfonso $\mathrm{X}^{6}$, podría estar relacionado con estas vías (ad quartum lapidem), aunque es probable que se deba a repartos de tierras medievales (alfoces y cuartos). El acceso a la ciudad debería realizarse por el único punto posible, el vado de La Anicoba a la altura de La Ribera, paso tradicional también de las vías ganaderas, Cañada de Valverde del Camino y Cañada de Sevilla, que siguen la estela de estas vías romanas. Estas cañadas entran en Huelva por la Barriada del Torrejón, y M.I. Ignacio Pérez Quintero describe el recorrido de esta vía que sale de Huelva al encuentro de ese cruce: ".. aún dura cerca de Huelva el camino que va a San Juan del Puerto, la antigua calzada de los Romanos, pasado el sitio que llaman Soledad del Camino por delante de la viña denominada de la Orden hasta la laguna, y continua a trozos hasta la Asomada, que es el paraje que da vista a la Ribera de la Anicoba, y desde aqui sigue abierta la calzada hasta San Juan del Puerto."

El yacimiento de Pajaritos es así un asentamiento rústico situado en la zona de explotación agrícola de la Huelva romana, en las cercanías de un lugar privilegiado desde el punto de vista de las comunicaciones, en la confluencia de las principales vías de acceso a la ciudad.

La riqueza agrícola del entorno de Huelva se refleja especialmente en sus amonedaciones de época romana. Las acuñaciones de Onoba plantean dos opciones con respecto a la localización de la ceca ${ }^{8}$, la Onoba del Conventus Cordubensis (¿El Carpio, Villafranca de Córdoba? ${ }^{9}$, o la Onoba Aestuaria, identificada tradicionalmente con la ciudad de Huelva. Los autores proclives a la primera opción hacen hincapié en que los tipos monetales de reverso (topónimo entre espigas tendidas) son más frecuentes en la campiña del Guadalquivir (Carmo, Caura, Callet, Searo y Cerit e Ilipla algo más alejadas) y se vinculan a producción agrícola, mientras que en Huelva, por su situación geográfica, deberían primar las pesquerías y utilizarse representaciones de peces, como en otras cecas de zonas costeras. Sin embargo, y aunque este sea un argumento sólo relativo, hasta el momento la producción de salsas y salazones en la costa de Huelva ofrece, como se ha indicado anteriormente, una cronología tardía, casi siempre bajo-imperial. Por el contrario, la cronología de las monedas más comúnmente admitida es de la primera mitad del siglo I a.C., momento en el que la economía de la Huelva romana pudo ser más dependiente tanto de la actividad portuaria relacionada con la salida de los metales de la zona del Andévalo como de la explotación de su rico entorno agrícola. Es un problema de difícil solución la determinación de la situación geográfica de la población que acuñaba las monedas de Onvba (de esta forma aparece el topónimo monetal), sólo los datos de procedencia de los hallazgos de estas piezas permitirían su correcta reducción, y en este sentido nos parece de interés señalar que

6 ANA Ma ANASAGASTI y LAUREANO RODRÍGUEZ, Niebla en época de Alfonso X, Huelva, 1984, 43.

7 M I. PÉREZ QUINTERO, La Beturia Vindicada ó ilustración crítica de su tierra, con la noticia de algunas de sus ciudades é islas, Sevilla, 1794, 78.

8 Cf. J. A. PÉREZ MACÍAS, La Huella de Roma, Huelva, 2006, 59.

9 CIL II²/7, 59, la sitúa en El Carpio. 
existen bastantes referencias escritas ${ }^{10}$ y orales ${ }^{11}$ sobre hallazgos realizados en Huelva y sus alrededores de unas monedas que, salvo algunas excepciones, no son raras pero si bastante escasas.

Las acuñaciones de Onvba a las que nos referimos tienen diferentes anversos mientras los reversos son los de topónimo entre espigas tendidas. Se considera correspondiente a la primera emisión uno de cabeza masculina desnuda que añade en el reverso creciente y letra A. Emisiones similares sin A ni creciente, de arte más descuidado, le seguirían en el tiempo; todas ellas comprenden solamente unidades. Las series últimas se componen igualmente de unidades, salvo una de ellas que presenta mitades también, e incluyen nombres de magistrados latinos, C. AELI, Q. PUBLILI y P. TERENT; otras leyendas, ET COL y CONIP.IL Q., generan la duda de si se refieren a magistrados indígenas o a otras fórmulas legales de difícil interpretación ${ }^{12}$.

\section{LA INSCRIPCIÓN}

El texto está grabado sobre un pedestal de estatua cilíndrico de caliza blanca con numerosas vetas que se van abriendo hasta convertirse en grietas de profundidad considerable, como la que recorre la pieza a lo largo, justo por la zona media (figura 3). Está recortado por arriba para ser reutilizado y la superficie, en esta parte, fue desbastada quizá para asegurar la fijación de una pieza encima. En la parte posterior tiene dos roturas, una arriba y otra abajo. Mide $130 \mathrm{~cm}$ de alto y 60 de diámetro. El campo epigráfico ocupa 62 × $68 \mathrm{~cm}$ y su última línea está a $58 \mathrm{~cm}$ de la parte inferior. Las letras, capitales de excelente ejecución, miden $7,5 \mathrm{~cm}$ en la primera y quinta línea y $7 \mathrm{~cm}$ en el resto; la interpunción es triangular. Se conserva en el Museo de Huelva (inv. n. 7527).

Entre ellas las de: A. DEL BARCO Y GASCA, Dissertación Histórico-Geográphica sobre reducir la antigua Onuba a la Villa de Huelva, Sevilla, 1755, 62-63 y 65, quien refiere dos hallazgos contemporáneos; las de M. IGNACIO PÉREZ QUINTERO, La Beturia Vindicada, Sevilla,1794, 79, que comenta otros dos; de A. DELGADO, Nuevo método de clasificación de las Medallas Autónomas de España, I, Sevilla, 1871, 249, que indica un hallazgo de 1855; y las sucesivas guías de Huelva de principios del siglo XX, por ejemplo J. FERNÁNDEZ DE LOS REYES, Guia de Huelva y su Provincia, Huelva, 1905, 59, que recogen la noticia de las muchas monedas de Onvba que se han encontrado en Huelva.

11 Son varias las noticias orales que sitúan hallazgos más recientes de piezas, alguna de ellas vistas por nosotros, así en las huertas de El Conquero, en el entorno del Instituto La Rábida, en la zona de La Ribera y junto al hipermecado Continente. Por tratarse de siete monedas, el más significativo de todos ellos es el del verterdero de la excavación de C/ Méndez Núñez-7-13 (1998), que por desgracia no hemos podido comprobar. A a ellos hay que añadir uno más, procedente de la intervención realizada (en 1992) por el Servicio de Arqueología de la Diputación Provincial en la clausura del convento de agustinas de Santa María de Gracia, en el corazón de la población romana. El único dato de encuentro casual fuera de la la zona de Huelva es el de nueve piezas en Los Palacios y Villafranca (Sevilla) en la decada de 1990. No se conoce, o al menos no se ha publicado, una densidad similar de hallazgos en la provincia de Córdoba.

12 Estas monedas en L. VILLARONGA, Corpus nummum Hispaniae ante Augusti aetatem, Madrid,1994, 387-388; FCA. CHAVES TRISTÁN, Las acuñaciones latinas de la Hispania Ulterior, Historia Monetaria de Hispania Antigua, Madrid, 1997, 233-317; Ma P. GARCÍA-BELLIDO, Formas y usos de las magistraturas en las monedas hispánicas, La moneda hispánica, Ciudad y Territorio, Anejos de Archivo Español de Arqueología, XIV, Madrid, 1995, 381-427; Ma P. GARCÍA-BELLIDO y C. BLÁZQUEZ, Diccionario de cecas y pueblos hispánicos, Madrid, 2001, I, 148, y II, 300-302. 


\author{
$[--.---]$ \\ sacrum \\ P(ublius) Porcius $\cdot$ Quir(ina) \\ Sisenninus \\ aedilis. IIvir \\ $5 \quad d(e) \cdot s($ ua $) \cdot p($ ecunia $) \cdot d($ edit $) \cdot d($ edicavit $)$.
}

La ejecución cuidada del titulus y su ordinatio, unido a la altura conservada, nos permiten suponer que por encima del primer renglón sólo hubiera habido una línea cuyos extremos izquierdo y derecho alcanzaran, como mínimo, el mismo margen que los de la tercera línea. Por ello esa primera línea habría podido tener en torno a doce letras iguales, o incluso algo más altas, que las de la segunda línea.

Cualquier restitución en la primera línea es insegura pues las posibilidades son múltiples: desde que la estatua consagrada hubiera estado relacionada con el culto imperial, por tanto, en la línea primera faltaría cualquier divinidad o abstracción augusta o, el nombre del mismo emperador siempre teniendo en cuenta, que la longitud de la línea sería en torno a doce letras lo que nos limitaría a una frase corta imposible de determinar, algo así como imp. divo Aug. o divo Augusto, Vespasiano, Tito etc., hasta una dedicación al Genius municipii ${ }^{13}$ o a cualquier divinidad del panteón romano.

Ahora bien, Publius Porcius Sisenninus ${ }^{14}$, magistrado que dedica la estatua tras cumplir la edilidad y el duumvirato en su civitas, estaba adscrito a la tribu Quirina. Como es bien sabido a esta tribu fueron adscritos, habitualmente, los municipia que recibieron el ius Latii en época flavia ${ }^{15}$. Así, esta primera mención de la tribus Quirina en una inscripción de Onoba introduce un nuevo elemento de juicio que contradice

13 Dos testimonios cercanos de culto imperial son el ara de Trigueros ( $c f$. J. BELTRÁN FORTES - A. U. STYLOW, Un aspecto del culto imperial en el Suroeste Bético: el "Puteal" de Trigueros (Huelva), un altar dedicado a Augusto, Culto Imperial: Política y Poder, Roma, 2007, 243-245), que se fecha en época tardoaugústea o tiberiana y el pedestal de estatua dedicado a Minerva Augusta por un decurio en Ilipula (J. GONZÁLEZ, Corpus de Inscripciones Latinas de Andalucía, Vol. I: Huelva, Sevilla, 1989, no 74).

14 Para Sisenninus vid. Sisininus (H. SOLIN - SALOMIES, Repertorium nominum gentilium et cognominum Latinorum, Hildesheim, Zurich, New York, 1988, 404; CIL IV 2264).

15 Sobre las posibilidades de interpretación de la presencia de más de una tribu en un mismo municipio $c f$. A.U. STYLOW, Apuntes sobre las tribus romanas en Hispania, Veleia, 12, 1995, 110; sobre la utilización de la tribus Quirina como elemento de identificación de municipios flavios, véase también el capítulo dedicado a la municipalización flavia en la Bética en E. ORTIZ DE URBINA, Las comunidades hispanas y el derecho latino, Vitoria 2000, 101 ss.; una puesta al día de los testimonios de la tribus Quirina en Hispania en J. ANDREU PINTADO, Apuntes sobre la Quirina tribus y la municipalización flavia de Hispania, Revista de Arqueología, 7 (1), 2004, 343-364, en el que vuelve a discutir la utilización de dicha tribu como argumento seguro de la promoción jurídica de las ciuitates tras la concesión del ius Latii a los hispanos por Vespasiano; del mismo autor, En torno al ius Latii Flavio en Hispania. A propósito de una nueva publicación sobre latinidad, Faventia, 29/2, 2007, 37-46, una reflexión sobre las repercusiones de la concesión del ius Latii en Hispania, la naturaleza y el proceso constituyente de los municipios a partir de ese derecho, en la que recoge y discute las opiniones precedentes. 
la consideración de que Huelva fue colonia romana ${ }^{16}$, cuyo argumento principal es la lectura de la inscripción de un lingote de cobre hallado en Marsella ${ }^{17}$. Las fuentes no mencionan su estatuto jurídico: Estrabón (Geogr. III, 2.5) destaca su singularidad al ser una ciudad construida en un estuario como Asta, Nabrissa, Ossonoba y Maeno$b a^{18}$; en Plinio (NH III, 7) no figura el nombre de Onoba sino un oppidum Ossonoba, Aestuaria cognominatum ${ }^{19}$, aunque parece haber unanimidad en aceptar que Aestuaria se refiere a $O n v b a^{20}$; y como punto de confluencia de varios caminos también se menciona en el Itinerario de Antonino (431.12) y en el Anónimo de Rávena ${ }^{21}$. Tampoco las leyendas de sus monedas aluden a su status jurídico, simplemente indican el topónimo Onvba, lo que no dejaría de sorprender si hubiera sido colonia.

Si bien sería arriesgado defender la promoción jurídica de Onoba únicamente por

16 Discusión con las diversas hipótesis en A. T. FEAR, Rome and Baetica: urbanization in southern Spain c. 50 BC-AD 150, Oxford, 1996, 121 y PÉREZ MACÍAS, op. cit., 64 ss.

17 La lectura no está exenta de dificultades y han sido distintas las propuestas F. BENOIT, Nouvelles épaves de Provence, Gallia 20, 1962, 154 ss., con foto: $m$ (etallum) p(ublicum) nomi(ne) uel imp(eratoris) nom(ine) / Primuli Silonis / CCXCVII / pro(curator) col(oniae) Ono/bensis, de donde la toma J. M. BLÁZQUEZ, Economía de la Hispania Romana al final de la República y comienzos del Imperio según Estrabón y Plinio, Estudios de Historia económica I, Revista de la Universidad de Madrid 20, 78, 1971, 38; M. EUZENNAT, Lingots espagnols retrouvés en mer, Études Classiques 3, 1968-1970, 95-97: Imp(eratoris) Antonin(i) / Primuli Silonis / CCXCVII / pr(ocuratoris) O[s]sono/b.a.nsis; F. LAUBENHEIMER-LEENHARDT, Recherches sur les lingots de cuivre et de plomb d'époque romaine dans les régions de Languedoc-Rousillon et de Provence-Corse, Paris 1973, 37, 78 ss. n. 16: Imp(eratoris) Antonin(i) / Primuli Silonis / CCXCVII I PROCOLONO/BENSIS; C. DOMERGUE, Les mines de la Péninsule Ibérique dans l'Antiquité romaine, 1990, 286-287 propone al final: pro[c(uratoris)] s(altu)s Lono/pensis uel pro[c(uratoris)] s(altu) S[.]lonol pensis. Sobre las distintas propuestas, $c f$. S. LAZZARINI, Lex metallis dicta: studi sulla seconda tavola di Vipasca, Roma 2001, 104 y PÉREZ MACÍAS, op. cit., 64 ss. No recoge LAZZARINI el desarrollo COL como col(legii) de FEAR (loc. cit. sup.) -que, por cierto, él mismo prácticamente descarta- y su sugerencia de interpretar pro(curator) Colonobensis. En cualquier caso este autor plantea la inseguridad de aceptar el estatus de colonia para Onoba en función de este único testimonio epigráfico cuya superficie tan corroída entorpece una lectura clara, así como las dificultades que entrańa el desarrollo pro(curator) pues no hay ejemplos de un procurador "being in charge, or being one of the officials, of any self-governing Roman community".

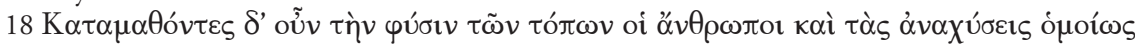

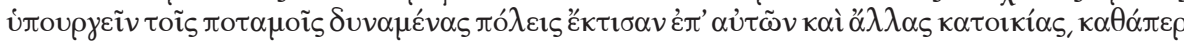

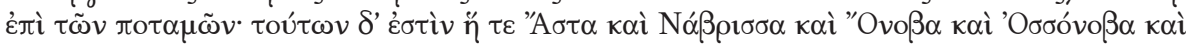

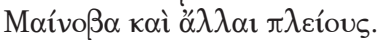

19 Baetica, a flumine mediam secante cognominata, cunctas provinciarum diviti cultu et quodam fertili ac peculiari nitore praecedit. iuridici conventus ei IIII, Gaditanus, Cordubensis, Astigitanus, Hispalensis. oppida omnia numero CLXXV, in iis coloniae VIIII, municipia c. R. X, Latio antiquitus donata XXVII, libertate VI, foedere III, stipendiaria CXX. ex his digna memoratu aut Latio sermone dicto facilia, a flumine Ana litore oceani oppidum Ossonoba, Aestuaria cognominatum, inter confluentes Luxiam et Urium, Hareni montes, Baetis fluvius, litus Curense inflexo sinu, cuius ex adverso Gadis inter insulas dicenda, promunturium Iunonis, portus Baesippo, oppidum Baelo, Mellaria, fretum ex Atlantico mari, Carteia, Tartesos a Graecis dicta, mons Calpe.

20 Alude a ello en la introducción al corpus epigráfico onubense, J. GONZÁLEZ, Corpus de Inscripciones Latinas de Andalucía. Tomo I. Huelva, Sevilla 1984, p. 128-129; véase además M. MAYER, Plinio el Viejo y las ciudades de la Baetica: Aproximación a un estado actual del problema, Estudios sobre Urso Colonia Iulia Genetiva (J. González, Ed.), Sevilla, 1989, 138.

21 Sobre las menciones de Onoba en las fuentes literarias $c f$. PÉREZ MACÍAS, op. cit., 68. 
esta mención de la tribus Quirina, no podemos obviar que en buena parte de civitates del Conventus Hispalensis con individuos adscritos a la Quirina, el mismo nombre del municipio asegura dicha promoción. Así ocurre en el caso de Arva (CILA 224, 225), Axati (CILA, 207), Canania (CILA 234), Munigua (CILA 1055, 1072, 1073 etc.), Naeva (CILA 271) o Salpensa (CILA 968), mientras que no se menciona en las inscripciones de Iporca (CILA 1048), Conobaria (CILA 994), Ilipula (CILAH 74), Ituci (CILAH 89) y Curiga (CIL II 1042) 22 con ciudadanos adscritos a la Quirina pero que, muy probablemente, habrían sido privilegiadas también por los flavios. Incluso en el pedestal onubense la falta de la primera línea no nos permite siquiera descartar la posibilidad de que hubiera sostenido una estatua del G(enius) m(unicipum) m(unicipii) $F$ (lavii) Onobensis. Lo que sí es seguro es que por el tipo de letra, la inscripción se fecharía entre época flavia y trajanea, aunque el asta transversa, a media altura, de la cifra del duumvirato nos inclina a una cronología más en el siglo I que en el II, pues a medida que avanza la primera centuria la línea que indica el numeral va superpuesta y no cruzando a las cifras; también la inscripción es del mismo tenor que otros tantos pedestales de estatuas u otros testimonios de evergesías de los ciudadanos de las élites locales, que alcanzaron la ciudadanía tras el cumplimiento de las magistraturas ciudadanas en sus municipios, privilegiados por los emperadores flavios.

22 En Ugultunia, Seria, Nertobriga y Segida, las otras ciudades de la Beturia céltica sólo hay testimonios epigráficos de la tribu Galeria, y en la zona de dicha región que hoy es territorio de Huelva, los encontramos en Aroche y Encinasola y fuera de ella en Ilipula y Ostur. Sobre la colonización de esta región y la promoción de sus ciudades $c f$. PÉREZ MACÍAS, op. cit., 44 ss. y en especial, Las inscripciones funerarias de comienzos del siglo I en Huelva, ¿migración o colonización?, Espacios, usos y formas de la epigrafía Hispana en épocas Antigua y Tardoantigua: homenaje al Dr. Armin U. Stylow, Madrid 2009, 285296, donde se sugiere que la presencia de estos ciudadanos adscritos a la Galeria podrían responder a adsignationes viritanae. 
